\title{
Test results from the full size prototype test of $\mathrm{W7-X}$ joint
}

\author{
K. Rummel ${ }^{1,{ }^{*}}$, M. Czerwinski ${ }^{1}$, F. Hurd ${ }^{1}$, A. John ${ }^{1}$, H. Lentz ${ }^{1}$, G. Czymek ${ }^{2}$, B. Giesen ${ }^{2}$, \\ F. Harberts ${ }^{2}$, S.A. Egorov ${ }^{3}$, V. E. Korsunsky ${ }^{3}$, I. Y. Rodin ${ }^{3}$, P. Bruzzone ${ }^{4}$, B. Stepanov ${ }^{4}$, \\ M. Vogel ${ }^{4}$ \\ ${ }^{1}$ Max-Planck-Institut für Plasmaphysik, Euratom Association \\ Teilinstitut Greifswald, Wendelsteinstr. 1, D-17491 Greifswald, Germany \\ ${ }^{2}$ Institut für Plasmaphysik, Forschungszentrum Jülich GmbH, Euratom Association, Trilateral \\ Euregio Cluster, D-52425 Jülich \\ ${ }^{3}$ Scientific Technical Center "Sintez", D. V. Efremov Scientific Research Institute of \\ Electrophysical Apparatus, 196641, Russia, St.-Petersburg, Metallostroy \\ ${ }^{4}$ CRPP-FT, CH-5232 Villigen-PSI, Switzerland
}

* Corresponding author Tel.: +49-3834-882722; Fax: +49-3834-882719;

E-mail address: kerstin.rummel@ipp.mpg.de

Key words: WENDELSTEIN 7-X, joint

\begin{abstract}
The superconducting fusion experiment WENDELSTEIN 7-X (W7-X) is presently under construction at the Greifswald branch of the Max-Planck-Institut für Plasmaphysik (IPP).

The magnet system consists of 50 non-planar and 20 planar coils which are connected by 121 bus bars in series of 10 groups of seven coils each. The connection of the bus bars will be provided by 184 joints each with a maximum allowable resistance of $5 \mathrm{n} \Omega$. The principle of such a joint was tested by two joints in SULTAN Test facility CRPP, Switzerland in 2003. Both joints showed resistances less than $1 \mathrm{n} \Omega$ at $25 \mathrm{kA}$ in a magnetic field of $2 \mathrm{~T}$. In the meantime efforts to modify the design of the casing and clamping parts for the serial production of joints have been carried out and tools for the installation at W7-X and mounting procedures were developed. The essential modifications and the latest test results at the SINTEZ of the Efremov Institute in St. Petersburg, Russia will be presented.
\end{abstract}

\section{Introduction}

The superconducting bus bars connecting the coils of W7-X are made of the same cable in conduit superconductor as the coils [1-3]. The electrical connection between coil terminals and bus bar ends is made by 184 special joints in a steel casing which must be installed in very exact positions in the experiment. In order to allow for possible repair and replacement the joint should be demountable. Contrary to the interlayer joints of the coils, where the maximum allowable electrical resistance is $1 \mathrm{n} \Omega$, the joints of the bus bar system have a maximum allowable resistance of $5 \mathrm{n} \Omega$. This higher allowance is due to the difficulty of assembly [3-5].

The joint is designed for an operating current of $18 \mathrm{kA}$ at a magnetic field of $2 \mathrm{~T}$. Depending on the cooling circuits with forced helium at $4.2 \mathrm{~K}$ and 6 bar there are two types of joint bodies. One type uses the helium flow coming from both conductor ends and leaves the joint through a pipe in the coil casing, the other uses the helium flow which enters the joint from the coil and leaves the joint through the bus bar. The joints for both cooling types are similar, the joints differ only in the helium pipe at the top of the cap where no helium separation is required. 


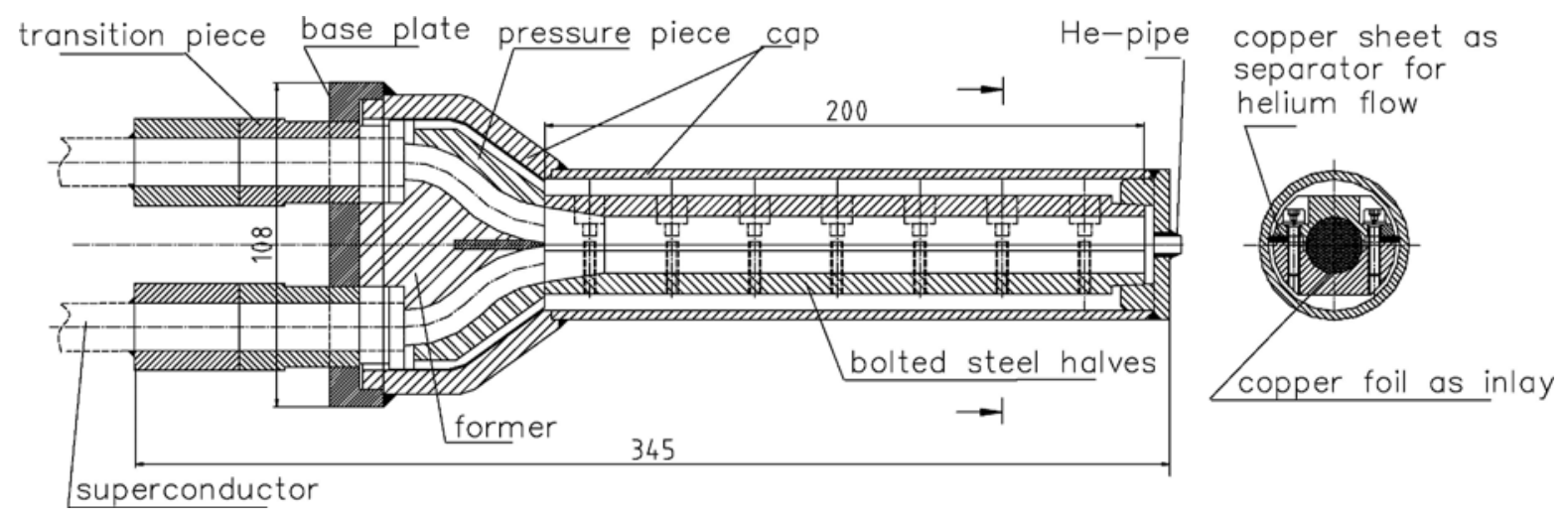

Fig. 1. Design of the joint

\section{Conductor}

The superconductor for $\mathrm{W} 7-\mathrm{X}$ is a forced flow cable-in-conduit conductor made from $243 \mathrm{NbTi}$ strands ( $3^{5}$, five stages cable). The strands have a diameter of $0.57 \mathrm{~mm}$ and are made of $144 \mathrm{NbTi}$ filaments stabilized by copper with a copper to non-copper ratio of 2.6. The twist pitches of the five cable stages are 25, $60,90,126$ and $147 \mathrm{~mm}$. The jacket is a co-extruded aluminum alloy. The conductor has a square cross section of $16 \times 16 \mathrm{~mm}$. The average diameter of the cable space is $11.4 \mathrm{~mm}$. The void fraction is $37 \%$.

The triplets of the conductor sections used for the full size samples have a critical current at $4.2 \mathrm{~K}$ and $5 \mathrm{~T}$ of $576 \mathrm{~A}$ and at $6 \mathrm{~T}$ of $472 \mathrm{~A}$. The Residual Resistivity Ratio is 194.

\section{Design of the joint prototype}

The basic design given in Fig. 1 is a 'praying hand' joint which can be de-and re-mounted in case of a malfunction of W7-X. The basic idea is that the aluminium jacket of the two superconductors is removed and the strands of both conductors are soldered and clamped together. To allow for easy welding the casing is made of stainless steel. From the procedure listed below a more detailed understanding of the basic joint design can be gained (see Figs. 1 and 2):

- Removing the jacket of both connector ends for length of $300 \mathrm{~mm}$.
- Untwisting of both cables to the first cable stage (triplet).

- Insertion of cables in transition pieces (aluminium /stainless steel) and TIG welding to the aluminium jacket.Tinning of each triplet (solder alloy $\mathrm{Sn} 60 \mathrm{~Pb} 40$ ).

- TIG welding of base plate of the casing and the transition pieces.

- Shaping of cable by special tooling.

- Pairing and soldering of the triplets of each cable (Fig. 3).

- Bundling of soldered triplet pairs and compacting by bolted steel halves with copper foil as inlay for a better current transfer along the clamp.

- Separation of helium flow by a copper sheet to force the direction of helium flow firstly through the conductor and then along the inside of the casing on the return, needed for the joint without helium pipe at the cap to allow for a sufficient cooling of clamped strands.

- Mounting and welding of joint cap to the base plate.

- Insulation of joint casing.

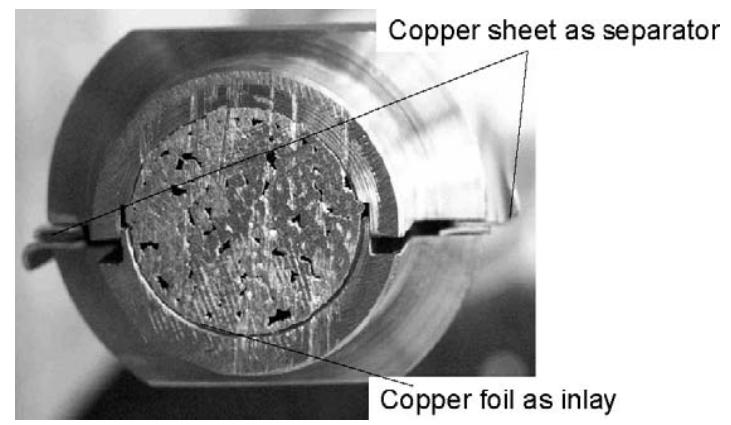

Fig. 2. View on the clamped strands. 


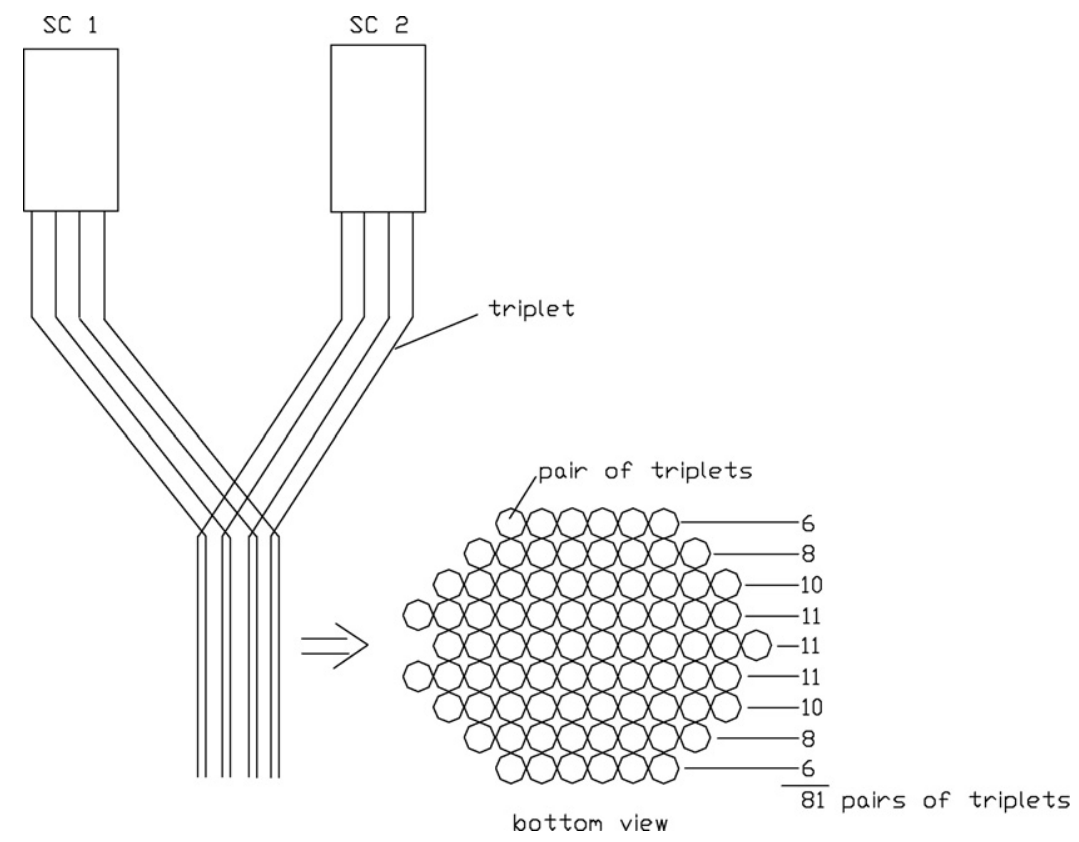

Fig. 3. Schematic for pairing and bundling of triplets.

The active length of the joint, i.e. the length where current transfer occurs, is $200 \mathrm{~mm}$. The strand volume in the joint is estimated at $25.68 \mathrm{~cm}^{3}$.

Two full size joint samples were built as "proof-of-principal" of the soldering procedure and the basic layout. These samples were assembled at IPP and were tested in the European test facility SULTAN at CRPP aluminium jacket. (Villingen, Switzerland) in 2003.

To investigate the influence of solder to the electrical resistance one sample was made using solder alloy $\mathrm{Sn} 60 \mathrm{~Pb} 40$ and the other was soldered with Sn95Ag5. The casing, which had originally a cylindrical geometry with maximum diameter $108 \mathrm{~mm}$, had to be modified to fit into the rectangular test well of SULTAN (96 mm $\times 144 \mathrm{~mm})$.

The instrumentation of the samples consists of voltage tap pairs and temperature sensors of CERNOX type. The facility sensors record the mass flow rate, pressure, dc field, ac field and sample current.

\section{Test results for the prototype joints at SULTAN}

4.1 Joint resistance

The joint resistance measured over a field range up to $2 \mathrm{~T}$ and a current range up to $25 \mathrm{kA}$ is very low, about $50 \mathrm{p} \Omega$ (Fig. 4). The voltage drop at $25 \mathrm{kA}$ is in the range of $1 \mu \mathrm{V}$. To improve the accuracy up to $\pm 5 \mathrm{p} \Omega$, an operating current $(25 \mathrm{kA})$ higher than the nominal one $(18 \mathrm{kA})$ was selected. Long acquisition time and signal smoothing techniques have also been applied.

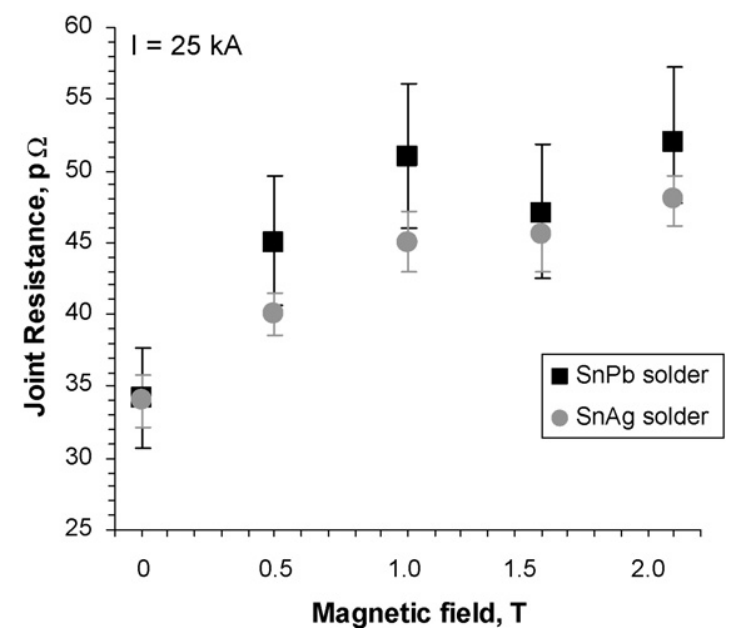

Fig. 4. Joint resistance vs. background magnetic field at $25 \mathrm{kA}$ operating current. 
The impact of the magneto-resistance of the copper matrix in the strand is visible in Fig. 4. As expected, the joint soldered with Sn95Ag5 alloy (resistivity $\approx 0.12 \mu \Omega \mathrm{cm}$ at $4.2 \mathrm{~K}$ ) has a lower resistance compared to the $\mathrm{Sn} 60 \mathrm{~Pb} 40$ solder (resistivity $\approx 0.21 \mu \Omega \mathrm{cm}$ at $4.2 \mathrm{~K}$ ). However, from an engineering point of view, the impact of magnetic field and solder resistivity is marginal.

At $25 \mathrm{kA}$ the power, $R I^{2}$, is limited to about $30 \mathrm{~mW}$, well below the resolution of the calorimetric method. In operation, it is likely that the ac loss power load exceeds the ohmic load at the joints.

It was not possible to quench the joint at $18 \mathrm{kA}$ and $2 \mathrm{~T}$ by heating a copper wrap around the electrical insulation up to $150 \mathrm{~K}$ during $3 \mathrm{~min}$. The reason for this was the effectiveness of the electrical insulation as a thermal insulator.

\subsection{AC losses}

The ac loss has been measured by gas flow calorimetry. The sinusoidal field over the whole joint length is orthogonal to the dc field of SULTAN which is always set at $2 \mathrm{~T}$. The set of measurement is taken at constant amplitude $( \pm 0.05 \mathrm{~T})$ and frequency range from 2 to $20 \mathrm{~Hz}$, at 0 and $18 \mathrm{kA}$ operating current, see Fig. 5. The ac power loss is normalized to the frequency and to the strand volume in the joint $\left(25.68 \mathrm{~cm}^{3}\right)$. The loss is substantially identical for both samples. At higher frequency, the joint with $\mathrm{SnAg}$ solder shows a slightly lower loss.

The ac loss in the joint, arbitrarily normalized as above in order to express the amount of energy lost per-cycle and perstrand-volume, results to be higher than the magnetic field energy density in the same volume. This means that, in this range of frequency, other components, e.g. the joint casing and the former and pressure piece, contribute substantially to the loss.

The impact of the transport current on the ac loss is small, in the range of $10 \%$. The trend is a reduction of the loss in presence of transport current, as already observed in other tests [6].

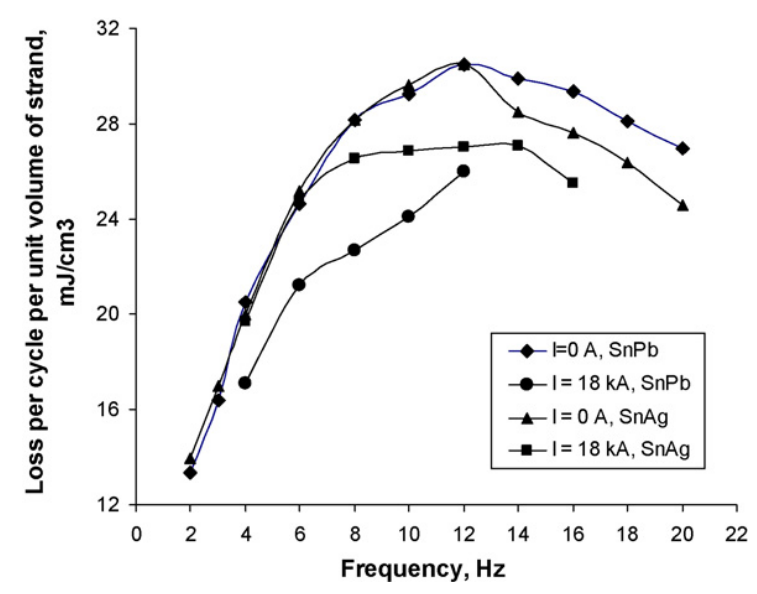

Fig. 5. Loss curves vs. frequency at 0 and $18 \mathrm{kA}$.

The joint ac loss at $20 \mathrm{~Hz}$ has contributions from both the soldered superconductor and the joint box. For an ac field amplitude of $10 \mathrm{mT}$, the ac loss is expected to be $0.1-$ $0.2 \mathrm{~W}$, compared to about $16 \mathrm{~mW}$ of $\mathrm{dc}$ load at $18 \mathrm{kA}$.

\section{Final joint design for the serial production}

The prototype test at SULTAN has shown a very low resistance and that the basic design is acceptable. In the case of the joint prototypes, these were manufactured under optimized working conditions in the workshop, the serial $\mathrm{W} 7-\mathrm{X}$ joint requires the following modifications [5]:

- Optimization of clamping design of the strands for ease of assembly.

- Nominal pressure of 170 bar [3] which can occur during quench.

- Reproducibility during assembly.

The design must allow for:

- Three times de- and re-mountibility

- Serial production of parts to reduce cost and ease of repair.

without changes of the principal strand connection and helium cooling flow.

In a framework of cooperation between the Forschungszentrum Jülich (FZJ) and IPP FZJ carried out the necessary activities to integrate these requirements in a new design of joint casing and clamping [7]. The SULTAN test have shown that there was no significant difference between the 
two solder alloys, therefore solder alloy $\mathrm{Sn} 60 \mathrm{~Pb} 40$ was chosen for the production joints.

The main modifications are the new clamping and the de-mountable thread connection and weld seam of the casing. The clamp which originally consisted of two steel halves and a copper sheet as separator for the helium flow is replaced by a combination of one copper and one steel half with a gold-plated steel bar as inlay (Fig. 6). The halves are bolted together before mounting the joint. This change significantly improves the mounting of the clamp over the strand bundle due to the compression of the bundle exerted by the inlaid bar.

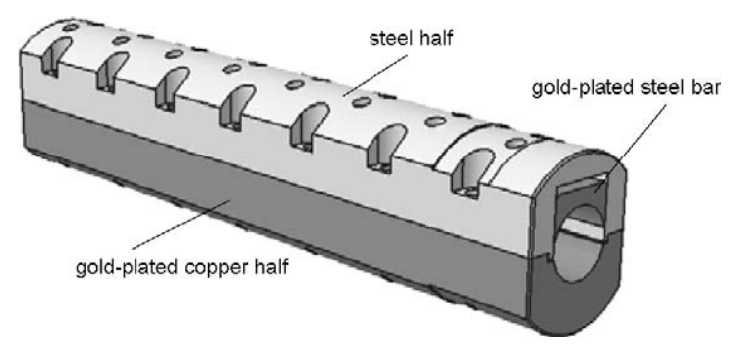

Fig. 6. Final clamp design.

The necessary separation of helium flow for the joints without helium pipe is done by an exact machining of the clamp and the cap of the casing.

To confirm the final design, including the assembly, of such a joint it was decided to perform a test. Due to the increased outer dimensions and the requirement to test a full size serial sample the test could not be repeated at SULTAN. The SINTEZ of the Efremov Institute at St. Petersburg offered to modify and extend their existing test facility to carry out the test comparable to the test conditions at SULTAN.

After extensive assembly trials using the serial design, tools to ease the assembly of joints were developed at IPP. A quality assurance and assembly plan including working instructions for the main steps were also developed and a full size sample was assembled under a typical constrained position at $\mathrm{W} 7-\mathrm{X}$.

\section{Test of the serial $W 7-X$ joint at the SINTEZ of the Efremov institute}

The measured resistance is less than $0.41 \mathrm{n} \Omega$ throughout the magnetic field range from 0 to $2.2 \mathrm{~T}$ at the nominal current of $18 \mathrm{kA}$ (Fig. 7). This value of resistance is far below the requested value of $5 \mathrm{n} \Omega$ and gives a comfortable safety margin for all possible uncertainties during assembly. The maximal dc load at $20 \mathrm{kA}$ could be estimated as $165 \mathrm{~mW}$ for each coil interconnection.

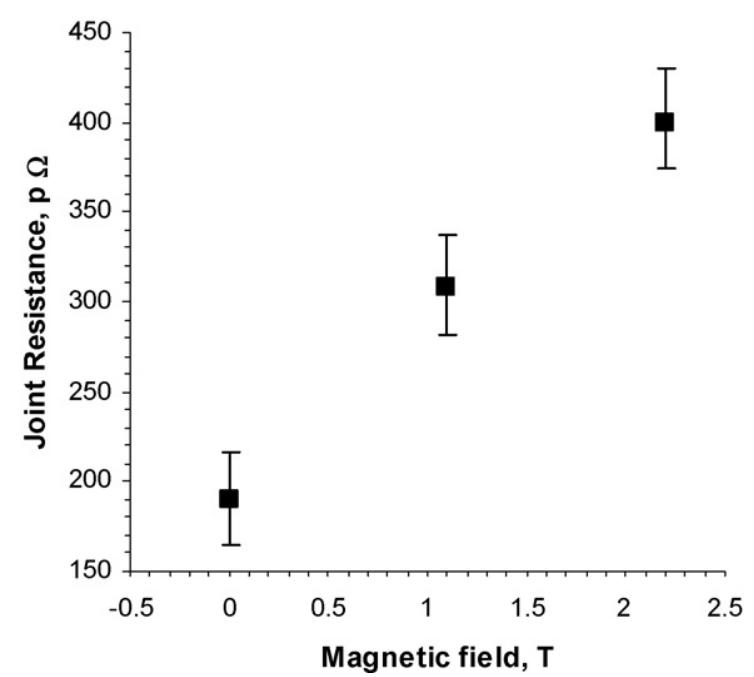

Fig. 7. Joint resistance vs. background magnetic field at $18 \mathrm{kA}$ operating current.

A quench in the joint could be initiated by increasing the helium temperature up to about $6.9 \mathrm{~K}$ at an operating current of $18 \mathrm{kA}$ and a field of $2 \mathrm{~T}$. That means for an operating temperature of $4.3 \mathrm{~K}$ at $\mathrm{W} 7-\mathrm{X}$ the temperature margin is about $2.6 \mathrm{~K}$.

The complete measurement of ac losses at $\pm 0.1 \mathrm{~T}$ in the range up to $20 \mathrm{~Hz}$ could not be performed with the existing test equipment. Only the joint ac losses at 2 and $3 \mathrm{~Hz}$ were measured as $2.77 \mathrm{~J} / \mathrm{s}$ at $2 \mathrm{~Hz}$ and $5.21 \mathrm{~J} / \mathrm{s}$ at $3 \mathrm{~Hz}$.

\section{Conclusion}

The principle objectives of the tests on the joints have been achieved. Both the tests at SULTAN and SINTEZ have confirmed that the joint has a resistance well below $1 \mathrm{n} \Omega$. The small differences in the results 
can be attributed to the difference in the test facilities and the various assembly changes. In practical terms the differences are extremely small.

The quench test at SINTEZ confirmed the expected temperature margin of $2.6 \mathrm{~K}$. The fact that the joint could not be quenched at SULTAN showed the original design to be robust.

Although the complete ac losses tests at SINTEZ still have to be performed the results of the other test indicate that problems are not expected.

\section{References}

[1] M. Wanner, V. Erckmann, J.-H. Feist, Status of WENDELSTEIN 7construction, Nucl. Fusion 43 (2003) 416-424.

[2] R.K. Maix, V. Bagnato, M. Fricke, K. Heyn, T. Kluck, F. Lange, K. Riße, C. Sborchia, N. Valle, Design, production and QA test results of the NbTi CIC conductors for the W7-X magnet system, J. Phys.: Conf. Ser. 43 (2006) 753-758.

[3] K. Stache, F. Kerl, J. Sapper, B. Sombach, L. Wegener, The superconducting busbar system of Wendelstein 7-X, Fusion Eng. Des. 66-68 (2003).

[4] L. Wegener, J.-H. Feist, J. Sapper, F. Kerl, F. Werner, Final design and construction of the Wendelstein 7-X coils, Fusion Eng. Des. 58-59 (2001).

[5] L. Wegener, The W7-X team, WENDELSTEIN 7-X at the transition to assembly, Fusion Eng Des. 74 (2005) 41-48.

[6] P. Bruzzone, R. Wesche, B. Stepanov, M. Vogel, Th. Gloor, Studies of subsize NbTi cable-in-conduit superconductors for ITER FEAT, IEEE Trans. Appl. Supercond. 13 (2003) 1456.

[7] B. Giesen, G. Czymek, F. Harberts, A. Panin, M. Czerwinski, H. Lentz, K. Rummel, M. Lennartz, U. Reisgen, W. Schuster, J. Wolters, M. Ebner, Design of the joints for the bus bar system of Wendelstein 7-X stellarator, Proceedings of the 24th Symposium on Fusion Technology, Warsaw 82 (2007) 1467-1472. 